\title{
Adult GH deficiency - the value of IGF-I estimation
}

\author{
Mara Boschetti \\ Claudia Teti \\ Manuela Albertelli \\ Francesco Minuto \\ Diego Ferone
}

Endocrinology Unit, Department of Internal Medicine \& Medical Specialties and Centre of Excellence of Biomedical Research, IRCCS AOU San Martino-IST, University of Genova, Italy

\author{
Address for correspondence: \\ Diego Ferone \\ Endocrinology Unit \\ Department of Internal Medicine \& Medical Special- \\ ties \\ Centre of Excellence of Biomedical Research \\ IRCCS AOU San Martino-IST \\ University of Genova \\ Viale Benedetto XV, 6 \\ 16132 Genova, Italy \\ E-mail: ferone@unige.it
}

\section{Summary}

In patients with growth hormone (GH) deficiency (GHD) the diagnostic value of IGF-I levels has been recently revisited. A normal IGF-I value does not exclude GHD, because its secretion is complex and depends by several factors other than $\mathrm{GH}$, such as age, nutritional status, obesity, as well as catabolic illness. Due to the complexity and costs of GH stimulation tests, several authors have analyzed the predictive and diagnostic value of the concentration of plasma IGF-I in patients suspected for GHD. The evaluation of IGF-I is also determinant to individualized dose-titration strategies, able to avoid the common adult side effects of substitutive therapy with recombinant GH. Current recommendations in clinical practice for $\mathrm{GH}$ replacement therapy, in GHD adults, agree on GH dosing regimens to be individualized independently of body weight using IGF-I levels as a biomarker of the treatment. For these reasons, in a clinical setting, appropriate normative values in different age groups in a large healthy population must be established in single laboratories, while, considering the relatively small sex difference, a different reference range for sex seems not necessary. This review discusses the more recent debated issues in the literature on the role of IGF-I, as well as other IGF system components, in the management of adult patients with GHD.

KEY WORDS: IGF-I; GH; IGFBPs; ALS; GH deficiency.

\section{Introduction}

Growth hormone (GH) deficiency (GHD) is nowadays a well-recognized clinical entity. It causes abnormalities in substrate metabolism, body composition, physical, and psychosocial function, which improve after recombinant GH (rhGH) replacement therapy. GHD is suspected from patient's pathological history and from clinical sign and symptoms of hypopituitarism (1).

Diagnosis of adult GHD is made by GH provocative tests and the most commonly used are the insulin tolerance test (ITT), GH releasing hormone $(\mathrm{GHRH})$ plus arginine test and glucagon test. Different cut-off values have been defined according to BMI (2) and the diagnostic value of IGF-I levels has been recently revisited $(1,2)$. In particular, very low IGF-I levels, in patients with an history and/or signs and symptoms highly suspected for GHD (presence of multiple pituitary hormone deficits), could be sufficient to confirm the diagnosis (see below). IGF-I is an appropriate screening test for GHD in young adult lean patients $(<40$ years, BMI $<25 \mathrm{~kg} / \mathrm{m}^{2}$ ), however, normal IGF-I levels do not rule out GHD at any age. The levels of IGF-I may depend on many factors other than $\mathrm{GH}$ secretion: above all, the nutritional status. Indeed, in undernourished patients, IGF-I levels are generally low. Currently, there are no suitable markers of $\mathrm{GH}$ activity alternative to IGF-I, although, IGF-I is only one of the many GH-dependent circulating peptides. Among these latter elements, the IGF binding protein 3 (IGFBP-3) and the acid labile subunit (ALS) of the $150 \mathrm{kDa}$ circulating complex have also been proposed as alternative parameters reflecting $\mathrm{GH}$ secretion (3). Excluding critically ill patients, the relative independence of ALS from substances known to affect the production of IGF-I and IGFBP-3 supports it for a potential use as a more specific parameter indicating $\mathrm{GH}$ secretory status. Further efforts are obviously necessary in order to develop age-specific normal values for ALS.

It is known that the analytical method influences the results of GH stimulation tests, however, similar problems exist for IGF-I as well. The classical immunoassay method for the measurement of IGF-I concentration, with acid-ethanol extraction to avoid the interference of binding proteins, has been widely used in the clinical practice since the early ' $80^{\text {ies }}$ 
Several papers reported studies on normal IGF-I levels in healthy subjects (4-8): IGF-I is lowest at birth and gradually increases with age reaching the peak in advanced puberty. In the adult state a decline of IGF-I values is reported with increasing age. In an Italian study, unlike other studies performed in Northern and Central Europe, no significant differences were found between sexes, in any group of age range, and an high variability of IGF-I values in the oldest people (8) has been reported as well. The gender difference observed in some studies might probably be due to the suppressive effect on IGF-I levels exerted by oral estrogens, largely used by women in Northern Europe (7).

For these reasons, in a clinical setting, appropriate normative values in different age groups in a large healthy population must be established in single laboratories, while, considering the relatively small gender difference, a separate reference range for sex is not necessary. Moreover, racial differences have been described as well: black men seem to display lower levels of IGFBP-3 and IGF-I and a greater IGF-I/IGFBP-3 ratio than white men across all ages, but younger than 70 (9). This picture is probably due to a genetic background, nutritional and social customs, physical activity and use or abuse of specific drugs.
There is a variety of methods of assay and kit materials available for IGF-I determination, but the validity and strength of reference values were demonstrated independently of the used method for IGF-I testing $(10,11)$. In conclusion, additional studies are necessary to develop age-specific reference ranges for IGF-I normal value in healthy subjects.

\section{IGF-I diagnostic value in patients suspected of GHD: not always GH stimuli}

Due to the complex, as well as expensively, GH stimulation tests, several authors have analyzed the predictive and diagnostic value of the concentration of IGF-I in plasma, in patients suspected for GHD $(4,12,13)$. Normal value of IGF-I does not exclude GHD, because the regulation of its secretion is complex and depends by several factors $(14,15)$. Moreover the timing of onset of GHD (childhood $v s$ adult), can modify IGF-I concentration, lower in childhood-onset than adult-onset GHD patients (16). Therefore, in panhypopituitaric patients and in suspected adult GHD patients with normal IGF-I and, without confounding factors, a GH provocative test is necessary to achieve the diagnosis $(5,12,13,17-19)$ (Fig. 1).

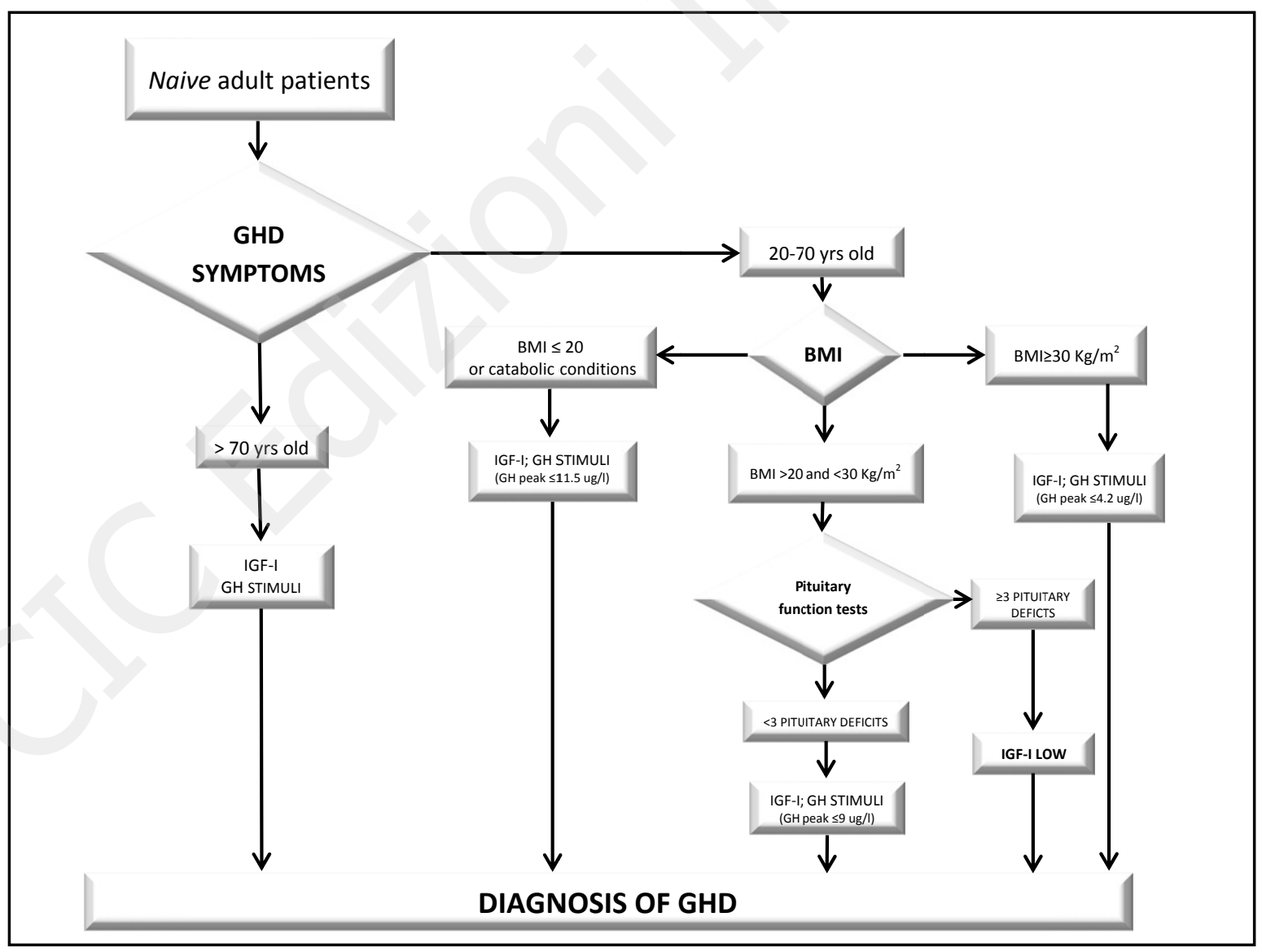

Figure 1 - The role of IGF-I in GHD diagnosis in naive adult patients. Cut-off values of GH peak are correct only after GHRH + arginine stimulation tests. As regard normal values of IGF-I the range of normality is defined for age range (as mentioned in the text). 
Total IGF-I has good intra-individual reproducibility and it is positively associated with the peak GH response to provocative tests (20). Based on these studies, we agree on the proposal that adult patients, with 3 or more pituitary deficits and low IGF-I, provocative tests are useless for the diagnosis of GHD. Similarly, a very low IGF-I level, in the absence of catabolic conditions or hypothyroidism, could be considered strongly suggestive for GHD, although the most recent guidelines still require $\mathrm{GH}$ stimulating tests in order to start the treatment with rhGH (21) (Fig. 1).

Childhood-onset GHD needs retesting in late adolescence or young adult hood. In the past, this issue raised questions about the most appropriate provocative test, as well as the cut-off value to be adopted. In patients with GHD of irreversible nature, such as post hypophysectomy, the simple measurement of IGF-I concentration, off rhGH for at least 1 month, could be sufficient. However, in presence of normal IGF-I values, a provocative test is mandatory in order to confirm or exclude the GHD $(21,22)$.

In the last years many authors have demonstrated that hypopituitarism, in particular GHD, is common among patients that have suffered from a traumatic brain injury, and the prevalence may vary from 10 to $25 \%$ $(23,24)$. In an interesting study in a series of patients with a documented history of moderate to severe traumatic brain injury the role of low IGF-I value to determine with a better accuracy the patients needing a screening for GHD has been emphasized (25). This is another example of a condition where IGF-I concentrations may have a better diagnostic value in the future, when the techniques of assay and the reference intervals will be definitively improved.

IGF-I in GHD patients treated with rhGH replacement therapy: dose titration

Dosing protocols have evolved from weight-based dosing (adopted in pediatric clinical practice) to individualized dose-titration strategies able to avoid the common adult side effects, such as paresthesias, peripheral edema, arthralgias and myalgias, caused by supra physiological levels of IGF-I $(21,26)$. It is well known that $\mathrm{rhGH}$ therapy requires careful monitoring to achieve maximal efficacy and to reduce potential adverse events. A reliable method, useful in monitoring patient responses to $\mathrm{rhGH}$, is needed to optimize $\mathrm{GH}$ dose adjustments.

Direct assessment of circulating $\mathrm{GH}$ levels during rhGH treatment is useless in monitoring patient response because $\mathrm{GH}$ is secreted by the pituitary in a pulsatile fashion, with a short half-life in blood. IGF-I, due to a more stable pattern of release (27) and a long half-life, has an established role in the monitoring of patient treatment (Fig. 2).

Treatment goal for adults with GHD is to reduce morbidity and mortality related to the hormone deficiency. The response to rhGH therapy in adults is variable: a dosing protocol that is suboptimal in one patient may be excessive in another one, while even normalization of IGF-I can induce side effects is some adult patients. In general, IGF-I concentrations, together with the clinical picture, as well as the metabolic parameters, should guide the physician in the therapeutic decisions (38) (Fig. 2). Current recommendations in clinical practice for GH replacement therapy, in GHD adults, agree on $\mathrm{GH}$ dosing regimens to be individualized, independently of the body weight, using IGF-I levels as a biomarker of the treatment $(29,30)$. The aim is to maintain IGF-I levels near the $50^{\circ}$ percentile for age or 1 SDS above the mean value for age $(1,29)$.

Age and gender have to be considered for rhGH dosing. Older patients should be treated initially with lower doses, that should be increased more slowly compared with younger subjects in order to avoid side effects, where as younger patients need higher doses. As previously stated, women, particularly those who are taking oral estrogen, usually may need higher doses of rhGH (31-34).

In panhypopituitary patients we should also take into consideration the potential interactions with other therapies, particularly replacement treatments, such as glucocorticoids: in patients taking adequate substitutive glucocorticoid therapy the response to $\mathrm{rGH}$ is higher than in patients overtreated. In the latter group IGF-I can be reduced, probably due to the effect of cortisol on GH-IGF-I axis (35).

Another factor that can influence IGF-I value during replacement treatment with rhGH is the Body Mass Index (BMI). Indeed, obese compared with non-obese patients have shown larger increment in IGF-I values after GH replacement therapy (36). By converse, low IGF-I levels have been found in patients with $\mathrm{GH}$ resistance due to malnutrition, and it is well known that while a low protein intake is able to increase IGF-I in the presence of adequate energy balance, there is a minimum value of energy intake below which even an optimal protein intake fails to obtain an increase in serum IGF-I (37). The mechanisms through which malnutrition decreases IGF-I value are different: reduction in the number of liver GH receptors, alteration of post-receptor pathways, reduction of circulating binding proteins, as well as other hormonal changes able to reduce IGF-I gene expression, such as insulin variation (37).

During replacement treatment, IGF-I levels should be monitored every 1-3 months in the phase of dose titration, and then semi annually (21). Finally, no conclusive data are available regarding the optimal daily timing of GH administration (evening or morning). This aspect is probably secondary, however needs more systematical evaluation (30).

Some interesting studies reported the effects of rhGH treatment on IGF-I and IGFBP-3 and demonstrated that IGFBP-3 is less sensitive than IGF-I to GH stimulation $(32,39)$. This phenomenon is probably due to a presumable direct effect of IGF-I, in addition to $\mathrm{GH}$, on synthesis and release of IGFBP-3, and justifies the reason why the response of IGFBP-3 is delayed with respect to IGF-I (37). Therefore, in study and management of patients affected by GHD, we should not exclude a possible role also for IGFBP-3, particularly in those situations in which we cannot have a reliable value of IGF-I. 


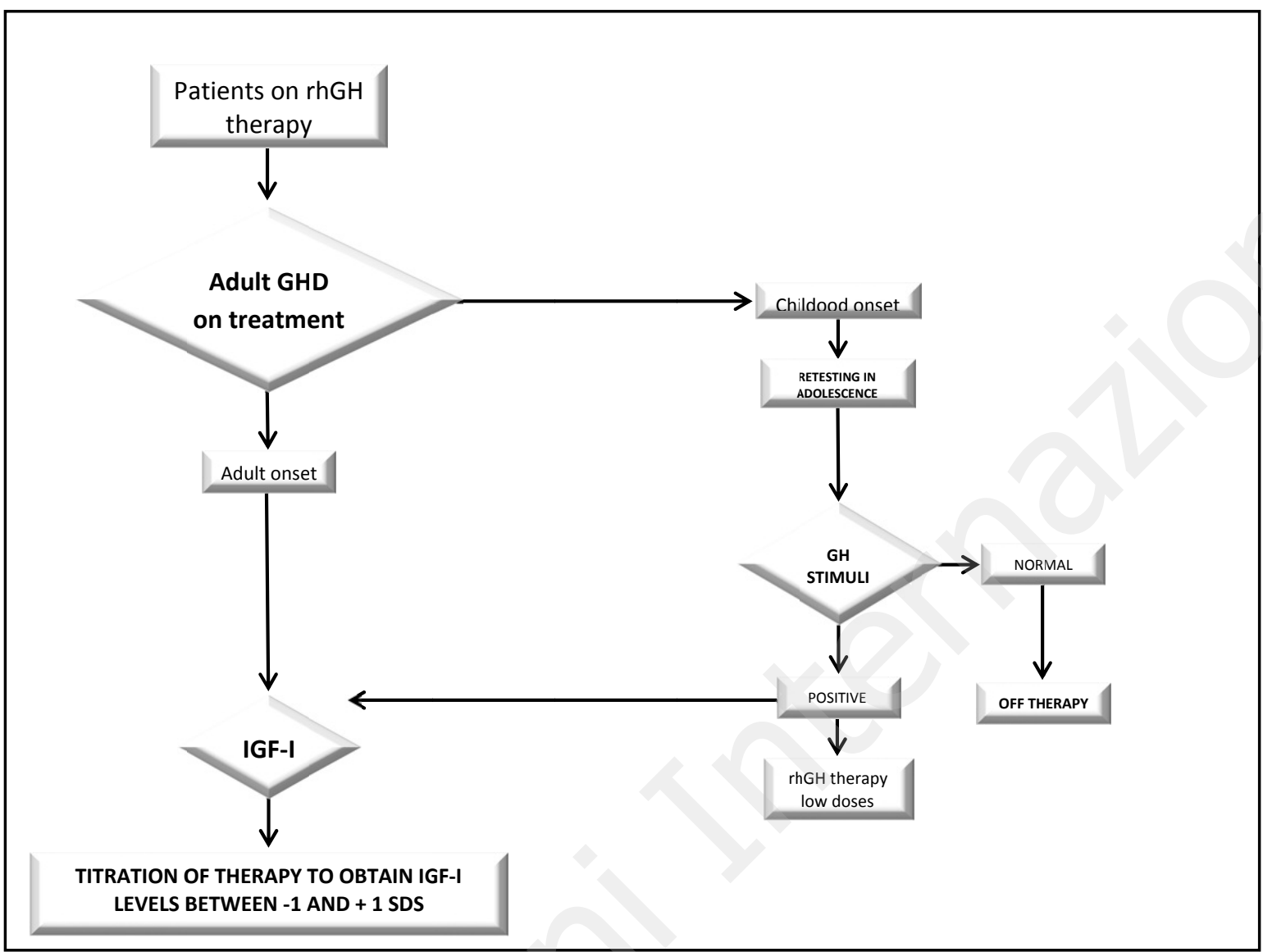

Figure 2 - The role of IGF-I in dose titration of rhGH replacementy therapy in adult GHD patients. The range of normality for IGF-I is defined for age range (as mentioned in the text).

\section{Conclusion}

Evaluation of IGF- I levels in patients is a crucial factor in the diagnosis of GHD and it is used for dose adjustment of rhGH replacement therapy. Due to the key role of IGF-I in the management of GHD appropriate reference values in different age groups in a large healthy population must be established and need to be further investigated.

\section{References}

1. Ho Ken KY. On be half of the 2007 GH Deficiency Consensus Workshop Participants. Consensus guidelines for the diagnosis and treatment of adults with GH deficiency II: a statement of the GH Research Society in association with the European Society for Pediatric Endocrinology, Lawson Wilkins Society, European Society of Endocrinology, Japan Endocrine Society, and Endocrine Society of Australia European. J Endocrinol 2007; 157:695-700.

2. Gasco V, Corneli G, Rovere S, et al. Diagnosis of adult GH deficiency. Pituitary 2008; 121-8.

3. Minuto F, Resmini E, Boschetti M, et al. Assessment of disease activity in acromegaly by means of a sin- gle blood sample: comparison of the 120th minute postglucose value with spontaneous $\mathrm{GH}$ secretion and with the IGF system. Clin Endocrinol 2004; 61:138-144.

4. Juul A, Holm K, Kastrup KW, et al. Free insulin-like growth factor I serum levels in 1430 healthy children and adults, and its diagnostic value in patients suspected of growth hormone deficiency. J Clin Endocrinol Metab 1997; 82(8):2497-502.

5. Juul A, Kastrup KW, Pedersen SA, et al. Growth hormone $(\mathrm{GH})$ provocative retesting of 108 young adults with childhood-onset GH deficiency and the diagnostic value of insulin-like growth factor I (IGF-I) and IGF-binding protein-3. J Clin Endocrinol Metab 1997; 82:1195-201.

6. Granada ML, Murillo J, Lucas A, et al. Diagnostic efficiency of serum IGF-I, IGF-binding protein-3 (IGFBP-3), IGF-I/IGFBP-3 molar ratio molar ratio and urinary $\mathrm{GH}$ measurements in the diagnosis of adult GH deficiency: importance of an appropriate reference population. Eur J Endocrinol 2000; 142:243-53.

7. Brabant $G$, von zurMühlen $A$, Wüster $C$, et al. Serum insulin-like growth factor I reference values for an automated chemiluminescence immunoassay system: results from a multicenter study. Horm Res 2003; 
60:53-60.

8. Aimaretti G, Boschetti M, Corneli G, et al. Normal age-dependent values of serum insulin growth factorI: Results from a healthy Italian population. J Endocrinol Invest 2008; 31:445-449.

9. McGreevy K, Hoel B, Lipsitz S, et al. Racial and anthropometric differences in plasma levels of insulinlike growth factor I and insulin-like growth factor binding protein-3. Urology 2005; 66:587-92.

10. Landin-Wilhelmsen K, Lundberg PA, Lappas G, et al. Insulin-like growth factor I levels in healthy adults. Horm Res 2004;62(1):8-16.

11. Ivan D. Brabant G, Kann PH. Applicability of recently established reference values for serum insulin-like growth factor 1: A comparison of two assays an (automated) chemiluminescence immunoassay and an enzyme-linked immunosorbent assay. Clin Lab 2005; 51:381-7.

12. Mukherjee A, Shalet SM. The value of IGF 1 estimation in adults with $\mathrm{GH}$ deficiency. Eur $\mathrm{J}$ Endocrinol 2009;161(1):33-39.

13. Gasco V, Corneli G, Rovere S, et al. Diagnosis of adult GH deficiency. Pituitary 2008; 11:121-8.

14. Hilding A, Hall K, Wivall-Helleryd IL, et al. Serum levels of insulin-like growth factor I in 152 patients with growth hormone deficiency. Eur J Endocrinol 2009; 84:2013-9.

15. Hartman ML, Crowe BJ, Biller BM, et al. Which patients do not require a GH stimulation test for the diagnosis of adult GH deficiency? J Clin Endocrinol Metab 2002; 87:477-85.

16. Attanasio AF, Lamberts SW, Matranga AM, et al. Adult growth hormone (GH)-deficient patients demonstrate heterogeneity between childhood onset and adult onset before and during human GH treatment. Adult Growth Hormone Deficiency Study Group. J Clin Endocrinol Metab 1997; 82:82-8.

17. Toogood AA, Beardwell CG, Shalet SM. The severity of growth hormone deficiency in adults with pituitary disease is related to the degree of hypopituitarism. Clinical Endocrinology 1994; 41:511-6.

18. Sönksen PH, Christiansen JS. Consensus guidelines for the diagnosis and treatment of adults with growth hormone deficiency. Growth Hormone Research Society. Growth Horm IGF Res 1998; 8 Suppl B:89-92.

19. Aimaretti G, Corneli G, Baldelli R, et al. Diagnostic reliability of a single IGF-I measurement in 237 adults with total anterior hypopituitarism and severe $\mathrm{GH}$ deficiency. Clin Endocrinol 2003;59:56-61.

20. Aimaretti G, Corneli G, Razzore P, et al. Usefulness of IGF-I assay for the diagnosis of GH deficiency in adult. J Endocrinol Invest 1998; 21:506-11.

21. Molitch ME, Clemmons DR, Malozowski S, et al. Evaluation and Treatment of Adult Growth Hormone Deficiency: An Endocrine Society Clinical Practice Guideline. J Clin Endocrinol Metab 2011; 96:1587609.

22. Gasco V, Corneli G, Beccuti G, et al. Retesting childhood-onset $\mathrm{GH}$-deficient patient. Eur J Endocrinol 2008; 159:S45-52.

23. Popovic V. GH deficiency as the most common pitu- itary defect after TBI: clinical implication. Pituitary 2005; 8:239-43.

24. Munoz A, Urban R. Neuroendocrine consequences of traumatic brain injury. Curr Opin Endocrinol Diabetes Obes 2013; 20:354-8.

25. Zgaljardic DJ, Guttikonda S, Grady JJ, et al. Serum IGF-I concentrations in a sample of patients with traumatic brain injury as a diagnostic marker of growth hormone secretory response to glucagon stimulation testing. Clin Endocrinol 2011; 74:365-9.

26. Hoffman AR, Strasburger CJ, Zagar A, et al. Efficacy and tolerability of an individualized dosing regimen for adult growth hormone replacement therapy in comparison with fixed body weight-based dosing. J Clin Endocrinol Metab 2004; 89:3224-33.

27. Brabant $G$, Wallaschofski $H$. Normal levels of serum IGFI: determinants and validity of current reference ranges. Pituitary 2007; 10:129-133.

28. GH research society. Growth Hormone Research Society Consensus guidelines for the diagnosis and treatment of growth hormone $(\mathrm{GH})$ deficiency in childhood and adolescence: summary statement of the GH research society. J Clin Endocrinol Metab 2000; 85:3990-3993.

29. Cook DM, Yuen KC, Biller BM, et al. American Association of clinical endocrinologists medical guidelines for clinical practice for growth hormone use in growth hormone-deficient adults and transition patients - 2009 update. Endocr Pract 2009; 15(2):1-29.

30. Pawlikowska-Haddal A, Cohen P, Cook DM. How useful are serum IGF-I measurements for managing $\mathrm{GH}$ replacement therapy in adults and children? $\mathrm{Pi}$ tuitary 2012; 15:126-134.

31. Cook DM, Ludlam WH, Cook MB. Route of estrogen administration helps to determine growth hormone (GH) replacement dose in GH-deficient adult. J Clin Endocrinol Metab 1999; 84:3956-60.

32. Ghigo E, Aimaretti G, Maccario M, et al. Dose-response study of $\mathrm{GH}$ effects on circulating IGF-I and IGFBP-3 levels in healthy young men and women. Am J Physiol 1999;276(6 Pt 1):E1009-13.

33. Hall K, Hilding A, Thorén M. Determinants of circulating insulin-like growth factor-I. J Endocrinol Invest 1999; 22(5):48-57.

34. Scaroni C, Ceccato F, Rizzati S, et al. Concomitant therapies (glucocorticoids and sex hormones) in adult patients with growth hormone deficiency. J Endocrinol Invest 2008; 31(9):61-65.

35. Filipsson $\mathrm{H}$, Monson JP, Koltowska-Haggstrom M, et al. The Impact of Glucocorticoid Replacement Regimenson Metabolic Outcome and Comorbidity in Hypopituitary Patients. J Clin Endocrinol Metab 2006; 91:3954-3961.

36. Yuen KC, Cook DM, Rumbaugh EE, et al. Individual IGF-I responsiveness to a fixed regimen of low-dose growth hormone replacement is increased with less variability in obese compared to non-obese adults with severe growth hormone deficiency. Horm Res 2006; 65:6-13.

37. Thissen JP, Ketelslegers JM, Underwood LE. Nutritional regulation of the insulin-like growth factors. Endocr Rev 1994; 15:80-101. 
M. Boschetti et al.

38. Gasco V, Prodam F, Grottoli S, et al. GH therapy in adult $\mathrm{GH}$ deficiency: A review of treatment schedules and the evidence for low starting doses. Eur J Endocrinol 2013; 168:R55-66.
39. de Boer H, Blok GJ, Popp-Snijders C, et al. Monitoring of growth hormone replacement therapy in adults, based on measurement of serum marker. J Clin Endocrinol Metab 1996; 81:1371-7. 